\title{
Scopolamine-Induced Delirium Promotes Neuroinflammation and Neuropsychiatric Disorder in Mice
}

\section{So Yeong Cheon}

Department of Biotechnology, College of Biomedical \& Health Science, Konkuk University, Chungju,

\section{Bon-Nyeo Koo}

Department of Anesthesiology and Pain Medicine, Yonsei University College of Medicine, Seoul

\section{So Yeon Kim}

Department of Anesthesiology and Pain Medicine, Yonsei University College of Medicine, Seoul

\section{Eun Hee Kam}

Department of Anesthesiology and Pain Medicine, Yonsei University College of Medicine, Seoul

\section{Junhyun Nam}

Department of Anesthesiology and Pain Medicine, Yonsei University College of Medicine, Seoul

\section{Eun Jung Kim ( $\nabla$ natlis@yuhs.ac)}

Department of Anesthesiology and Pain Medicine, Yonsei University College of Medicine, Seoul

\section{Research Article}

Keywords: scopolamine, postoperative delirium, postoperative cognitive dysfunction, neuroinflammation, inflammasome, microarray, neuropsychiatric disorder

Posted Date: December 30th, 2020

DOI: https://doi.org/10.21203/rs.3.rs-132211/v1

License: (c) (1) This work is licensed under a Creative Commons Attribution 4.0 International License. Read Full License

Version of Record: A version of this preprint was published at Scientific Reports on April 16th, 2021. See the published version at https://doi.org/10.1038/s41598-021-87790-y. 


\section{Abstract}

Postoperative delirium is a common neuropsychiatric syndrome resulting a high postsurgical mortality rate and decline in postdischarge function. Extensive research has been performed on both human and animal delirium models due to their clinical significance, focusing on systematic inflammation and consequent neuroinflammation playing a key role in the pathogenesis of postoperative cognitive dysfunctions. Since animal models are widely utilized for pathophysiological study of neuropsychiatric disorders, this study aimed at examining the validity of the scopolamine-induced delirium mice model with respect to the neuroinflammatory hypothesis of delirium.

Male C57BL/6 mice were treated with intraperitoneal scopolamine $(2 \mathrm{mg} / \mathrm{kg})$. Neurobehavioral tests were performed to evaluate the changes in cognitive functions, including learning and memory, and the level of anxiety after surgery or scopolamine treatment. The levels of pro-inflammatory cytokines (IL-1区, IL-18, and TNF-a) and inflammasome components (NLRP3, ASC, and caspase-1) in different brain regions were measured. Gene expression profiles were also examined using whole-genome RNA sequencing analyses to compare gene expression patterns of different mice models.

Scopolamine treatment showed significant increase in the level of anxiety and impairments in memory and cognitive function associated with increased level of pro-inflammatory cytokines and NLRP3 inflammasome components. Genetic analysis confirmed the different expression patterns of genes involved in immune response and inflammation and those related with the development of the nervous system in both surgery and scopolamine-induced mice models.

The scopolamine-induced delirium mice model successfully showed that analogous neuropsychiatric changes coincides with the neuroinflammatory hypothesis for pathogenesis of delirium.

\section{Introduction}

Postoperative cognitive dysfunction (POCD) is a common complication of the central nervous system postsurgery with manifestations such as damage to memory, mental capacity, language ability, or other aspects of cerebral function ${ }^{1}$ and with an acute phase of cognitive impairment defined as postoperative delirium (POD) ${ }^{2}$. POD shows characteristic clinical features such as inattention, mood changes, and psychiatric disorders ${ }^{3}$. POCD and POD have been associated with clinically significant adverse outcomes, including prolonged hospitalization, decreased quality of life, increased postoperative complications, and mortality ${ }^{4,5}$. As the exact mechanism of POCD and POD remains to be explored, the activation of inflammation and immune systems is strongly regarded as the key mechanism for cognitive deterioration postsurgery ${ }^{6}$. Surgery and anesthesia unleash a body-wide inflammation releasing peripheral inflammatory cytokines affecting the integrity of the blood brain barrier, thus allowing increased infiltration of inflammatory factors and macrophages into the brain ${ }^{7}$. 
Forebrain cholinergic neurons play a fundamental role in controlling the central nervous system with regards to attention, memory and cognitive function, and are implicated in cognitive decline and several neurodegenerative diseases ${ }^{8-10}$. The impact of cholinergic pathways on the immune system is also welldocumented ${ }^{8}$ showing that systemic inflammatory responses are under the control of the cholinergic anti-inflammatory pathway supplied by connections of the vagus nerve ${ }^{8,11}$. In a similar context, experimental and clinical studies focusing on the pathogenesis for delirium show that it is accompanied by cholinergic pathways and agents ${ }^{12,13}$.

Scopolamine is an anti-cholinergic drug that antagonizes the muscarinic cholinergic receptors (mAChRs) and is capable of producing deficits in the processes of learning acquisition, and consolidation ${ }^{14}$. Scopolamine-treated animal models are widely used in neurocognitive studies because scopolamine administration induces both the behavioral and molecular features of Alzheimer's disease and other neurocognitive disorders, including impaired cognition, increased oxidative stress, and imbalanced cholinergic transmission in the hippocampus and prefrontal cortex ${ }^{15-17}$. However, scopolamine treatment has also been reported to show opposite effects such as anti-depressant and anti-anxiety effects ${ }^{18}$.

Despite the highly analogous clinical traits and alterations in cholinergic neurotransmission by sustained neuroinflammation in scopolamine-treated animal models ${ }^{19}$, the reproducibility of the exact pathogenesis of POD still remains insufficient. The aim of this study was to validate the effectiveness of scopolamine-treated animal models as POD experimental model, by identifying the change in inflammation-related cytokines and candidate genes using RNA sequencing technology by comparing a scopolamine-induced delirium mice model and surgery mice.

\section{Methods}

\section{Animals and Ethics Statement}

Male C57BL/ 6 mice aged 9-12 weeks (25 $28 \mathrm{~g}$ ) from Orient Bio (Seongnam, Gyeonggi-Do, South Korea) were used for the experiment. All in vivo experimental procedures were certified and approved by the Institutional Animal Care and Use Committee (IACUC) of Yonsei University Health System, which is certified by the Association for Assessment and Accreditation of Laboratory Animal Care International (AAALAC). All experimental procedures were conducted according to the guide for the care and use of laboratory animals ( $8^{\text {th }}$ edition) by the National Research Council Committee, USA. All mice were housed under controlled environment with 12-h light/dark cycles and temperature, and ad libitum access to chews and water in a specific pathogen-free (SPF) facility at the Yonsei Biomedical Research Institute. The present experiment was performed according to an approved animal protocol (No. 2016-0335). The study is reported in accordance with the ARRIVE guidelines for reporting experiments involving animals (http://www.nc3rs.org.uk/arrive-guidelines).

\section{Experimental Design and Procedure}


The mice were assigned into three groups using appropriate randomization methods: 1) a vehicle-treated control group (control) ( $n=10$, male), 2 ) a surgery group (surgery) ( $n=10$, male), and 3 ) a scopolaminetreated group (scopolamine) ( $n=10$, male). Mice in the control group were kept unaffected to the experimental conditions, while mice in the surgery group underwent abdominal surgery as a positive control for the scopolamine-treated group. For the scopolamine-treated group, scopolamine (2 mg/kg) was dissolved in sterile saline $(0.9 \% \mathrm{NaCl} w / \mathrm{v})$ with the volumes for the administration prepared according to the body weight. Mice in the surgery group performed behavioral test at day 4 and 5 postsurgery. Mice in both the control and scopolamine-treated group performed behavioral test at day 1 before scopolamine or vehicle treatment. At day 2, the mice were injected with scopolamine intraperitoneally 30 minu before the neurobehavioral tests. The same amount of sterile saline was administrated into mice of the control group at 30 min before the neurobehavioral tests (Figure 1A and B). The surgical procedure was as follows. In the surgery group, mice were anesthetized with $4 \%$ isoflurane and were maintained with 1.5-2 \% isoflurane in oxygen at a flow rate of $1 \mathrm{~L} / \mathrm{min}$. Mice were placed on a heating pad during anesthesia to prevent hypothermia. Abdominal surgery was performed as mentioned previously, with some modifications ${ }^{20,21}$. After vertically incising along the midline, following the linea alba, mesenteric artery was clipped for $20 \mathrm{~min}$, and intestines were rubbed for $30 \mathrm{sec}$. The exteriorized abdominal muscle and skin were placed back into the peritoneal cavity and closed using sutures. Mice were returned to the home cage. At day 5 postsurgery, mice brains, including the hippocampus, prefrontal cortex, and amygdala, were isolated after sacrifice.

\section{Neurobehavioral Assessment}

The neurobehavioral findings of the mice were assessed using the open field test (OFT), elevated plus maze (EPM) and novel object recognition test (NORT). The behavioral tests were performed 30 min after drug administration according to the treatment plan. All the neurobehavioral tests were recorded on video and analyzed with an image analyzing system (SMART v2.5.21 software and SMART video tracking system, Panlab Harvard Apparatus, Barcelona, Spain) by an assessor blinded to the treatment groups. The mice sequentially performed the OFT, EPM and NORT.

\section{Open Field Test}

Mice were placed in a square open field arena $(40 \times 40 \times 40 \mathrm{~cm})$, were allowed to explore for $5 \mathrm{~min}$, and the behaviors were recorded simultaneously. Total distance moved was used as a measure of general activity and locomotor function. The animal's tendency to avoid the center area reflects the anxiety related behavioral change ${ }^{22}$.

\section{Elevated Plus Maze}

The EPM was performed to evaluate anxiety related behavior, learning, and memory functions of the mice. The maze consisted of two open arms $(31 \times 6 \times 1 \mathrm{~cm})$ and two closed arms $(31 \times 6 \times 15 \mathrm{~cm})$ extended from a central platform $(5 \times 5 \times 1 \mathrm{~cm})$, and was elevated to a height of $50 \mathrm{~cm}$ (JEUNGDO Bio \& Plant Co., Ltd.) from the floor. The mice were trained prior to surgery and tested at day 5 postsurgery. 
Mice were individually placed at the end of the open arm facing the other open arm and were allowed to explore for $5 \mathrm{~min}$. The total duration of time spent in the open and closed arms was recorded respectively. The apparatus was cleaned with $70 \%$ ethanol prior to all tests. Entry was defined as the placement of all paws into the arms of the maze. The percentage of time spent in the open arms was also measured. Learning index was calculated as follows: learning index = the first latency time to enter the closed arm (training period) - the first latency time to enter the closed arms (test period). The duration of time spent in the open arms also reflects anxiety related behavior ${ }^{23}$.

\section{Novel Object Recognition Test}

NORT was performed to evaluate cognition, especially recognition memory in the mice ${ }^{24}$. During the habituation phase, each mouse was allowed to explore the square box $(40 \times 40 \times 40 \mathrm{~cm})$ freely for 5 min. During the familiarization phase, the mice were placed into the box, which contained two identical objects $(A+A)$, and were allowed to explore for 5 min. During the test phase, each mouse was returned to the box with the two objects, where one object was changed into a novel object $(A+B)$, and mice were allowed to explore for $5 \mathrm{~min}$. During both the familiarization and the test phases, time spent in exploring each object was measured and recorded. At the end of each test, the apparatus and objects were cleaned with $70 \%$ ethanol. The habituation phase was performed immediately prior to surgery, the familiarization phase was performed at day 4 postsurgery, and the test trial was performed at day 5 postsurgery. The discrimination index was evaluated as (time taken to explore novel object B) / (time taken to explore novel and familiar objects) $\times 100$, which reflects cognitive ability.

\section{Enzyme-linked immunosorbent assay (ELISA)}

For the in vivo cytokine experiment, the hippocampus, prefrontal cortex, and amygdala of mice were obtained at day 5 postsurgery after the neurobehavioral tests and stored at $-80^{\circ} \mathrm{C}$ until use. To measure the levels of TNF- $a, \mathrm{IL}-1 \mathrm{Q}$, and IL-18 in the three different regions, brains were lysed using tissue protein extraction reagent (T-PER ${ }^{\circledR}$ Tissue Protein Extraction Reagent, Thermo Scientific ${ }^{\mathrm{TM}}$, Waltham, MA, USA) containing protease and phosphatase inhibitor cocktail (100X Halt protease and phosphatase inhibitor cocktail, \#1861281 Thermo Scientific ${ }^{\mathrm{TM}}$ ). The tissues were then homogenized and centrifuged at 13,000 rpm for 10 min to obtain sample supernatants. Supernatant protein concentrations were measured with a BCA Protein Assay Kit (Thermo Scientific ${ }^{\text {TM}}$ ) according to the manufacturer's specifications. Levels of TNF-a, IL-1区, and IL-18 in the lysates were assayed using high-sensitivity ELISA kits (Quantikine ${ }^{\circledR}$ ELISA, R\&D Systems Inc., Minneapolis, MN, USA) according to the manufacturer's specifications. Briefly, samples were added to the assay plates at a volume of $50 \mu \mathrm{L} /$ well and incubated for $2 \mathrm{~h}$ at room temperature. After washing plates with the wash buffer from the kit, TNF-a, IL-1区, and IL-18 conjugates were added to each well and incubated for $2 \mathrm{~h}$. The absorbance of each well was measured at $450 \mathrm{~nm}$ using a microplate reader. To measure the levels of NLR family pyrin domain-containing protein 3 (NLRP3), apoptosis-associated speck-like protein containing a C-terminal caspase recruitment domain (ASC), and caspase- 1 in lysates, ELISA kits from MyBioSource (San Diego, CA, USA) were used for this assay, and all procedures followed manufacture's instruction. 


\section{RNA Extraction and Gene Expression Profiling}

Total RNA from mouse brain tissue was extracted using Trizol reagent (Invitrogen, Carlsbad, CA, USA). RNA quality and quantity were assessed using Agilent 2100 bioanalyser (Agilent Technologies, USA) and ND-1000 spectrophotometer (NanoDrop Technologies, USA), respectively. RNA samples were used as input into the Affymetrix procedure (Affymetrix, Santa Clara, CA, USA) as recommended by protocol (http://www.affymetrix.com), of which total RNA from each sample was converted to double-strand cDNA. Amplified RNA (cRNA) was generated from the double-stranded cDNA template through an IVT (in vitro transcription) reaction using a random hexamer incorporating a T7 promoter and purified with the Affymetrix sample cleanup module. cDNA was regenerated from a random-primed reverse transcription using a dNTP mix containing dUTP. UDG and APE 1 restriction endonucleases were used for fragmenting cDNA, which was then end-labelled by terminal transferase reaction incorporating a biotinylated dideoxynucleotide. Fragmented end-labeled cDNA was hybridized to the Affymetrix arrays for 16 hours $\left(45^{\circ} \mathrm{C}\right.$ and $60 \mathrm{rpm}$ ) as described in the Gene Chip Whole Transcript (WT) Sense Target Labeling Assay Manual (Affymetrix). The chips were stained using SAPE (Streptavidin Phycoerythrin), washed in a Genechip Fluidics Station 450 (Affymetrix) and scanned using Affymetrix Model $30007 \mathrm{G}$ scanner. The scanned image data were extracted through Affymetrix Command Console 1.1 software to generate raw CEL files, which show expression intensity data. Expression data were generated by Transcriptome Analysis Console 4.0.1. For the normalization, RMA (Robust Multi-Average) algorithm implemented in Transcriptome Analysis Console software was used.

\section{RNA Sequencing Analysis of Differentially Expressed Genes}

Genes with a more than two-fold difference in the normalized signals compared to those in control group were selected as differentially expressed genes (DEG). Gene ontology analysis of the DEGs was performed by exDEGA (Excel based Differentially Expressed Gene Analysis, eBIOGEN, Inc., Seoul, Korea) tool. Categorization of the genes was based on a search performed using DAVID v6.8 (http://david.abcc.ncifcrf.gov). In each group, gene expression level was converted to a log2 value, and the relative level with respect to the control group was presented. The clustering heatmap profiles of DEGs were compared across the experimental groups using the Multiple Experiment Viewer software program v4.9 (MeV). The average fold change (FC) for each gene was expressed as a standardized zscore.

\section{Statistical Analysis}

Statistical analyses were performed using SPSS v25.0 (IBM, Armonk, NY, USA) and GraphPad Prism 7.00 software (GraphPad Software, San Diego, CA, USA). Values are presented as mean \pm standard error of the mean (SEM). Unpaired $t$-tests were performed to determine statistical significance. $p$-values $<0.05$ were considered significant.

\section{Data Availability}


All data supporting the conclusions of this manuscript are provided in the text and figures.

\section{Results}

\section{Scopolamine Treatment Induces Delirium-like Cognitive Dysfunction in Mice}

Delirium is related to accelerated cognitive dysfunction ${ }^{2}$. Therefore, we examined the role and validity of scopolamine treatment as the POD model by causing cognitive impairment, similar to POCD caused by the abdominal surgery model. Behavioral tests of EPM and NORT were carried out to assess the changes in learning and memory of mice before/after surgery or scopolamine treatment (Fig. 2). During the EPM test, surgery mice exhibited significant decrease in learning index as compared to control group, which indicates POCD. Similarly, scopolamine-treated mice displayed a significant drop in learning index with no difference between the surgery and scopolamine groups (Fig. 2A), as compared to mice from the control group. The mice were made to perform the NORT to examine hippocampal-dependent learning and memory. The duration of time spent exploring the novel object (calculated in percentage using the formula) significantly decreased in the surgery and scopolamine-treated groups, emphasizing the effect of surgery and scopolamine treatment on impairment of cognitive ability (Fig. 2B). The SMART video tracking system showed real-time tracking of each groups in NORT (Fig. 2C). Conclusively, neurobehavioral tests indicated that scopolamine treatment significantly caused memory impairments and decrease in cognition in mice, similar to the results seen in mice of the surgery group.

\section{Transcriptome Analysis Shows Scopolamine Treatment Alters Gene Expression Pattern in the Hippocampus}

To investigate whether surgery or scopolamine treatment affects the gene expression pattern in animal models, we used RNA sequencing analysis to compare the gene expression of hippocampal samples from control, surgery, and scopolamine-treated mice (Fig. 3 and Table 1). The heat map showed the twoway hierarchical clustering comparing the gene expression levels among different groups: surgery or scopolamine (Fig. 3A). Dock8, Myo1f, Trem/2, Gas5, Lpar2, and Ralbp1, were upregulated or downregulated after surgery or scopolamine treatment. The normalized repeatability coefficient (RC) of Dhx58, which is involved in process of the immune system, was upregulated in both the surgery and scopolamine-treated groups, as compared to the control group. The gene expression levels of Dock8, Myo1f, and Trem/2 were downregulated in both the surgery and scopolamine-treated groups. In the case of Gas5, only the surgery group showed downregulated level, as compared to the control. Only the scopolamine-treated group exhibited upregulated levels of $L$ par2. Compared to the surgery group, the level of Ralbp 1 was downregulated in both the control and scopolamine-treated groups (Fig. 3B). In addition, genes involving hippocampal function and the nervous system, such as Lrrn4, S100a10, S/c5a7, and Wnt6 were altered by surgery or scopolamine treatment. Gene expression of Lrrn4 and S100a10 was upregulated, while that of $S / c 5 a 7$ was downregulated in both the surgery and scopolamine-treated groups, as compared to the control group. However, only the scopolamine-treated group showed efficiently downregulated expression of Wnt6, as compared to the control and surgery groups (Fig. 3C). 
Table 1. Differentially expressed genes in surgery and scopolamine-treated mice. 


\begin{tabular}{|c|c|c|c|c|c|c|}
\hline \multicolumn{3}{|c|}{ Surgery } & \multicolumn{2}{|c|}{ Scopolamine } & \multirow[t]{2}{*}{ Gene Description } & \multirow{2}{*}{$\begin{array}{l}\text { GO biological process } \\
\text { (gene function) }\end{array}$} \\
\hline & FC & $\begin{array}{l}p- \\
\text { value }\end{array}$ & FC & $\begin{array}{l}p- \\
\text { value }\end{array}$ & & \\
\hline \multicolumn{7}{|c|}{ Inflammation / Immune response } \\
\hline \multirow[t]{2}{*}{ Dhx58 } & 1.516 & 0.003 & 1.488 & 0.020 & $\begin{array}{l}\text { DEXH (Asp-Glu-His) box } \\
\text { polypeptide } 58\end{array}$ & $\begin{array}{l}\text { Immune system } \\
\text { process }\end{array}$ \\
\hline & & & & & & $\begin{array}{l}\text { Regulation of Innate } \\
\text { immune response }\end{array}$ \\
\hline \multirow[t]{2}{*}{ Dock8 } & 0.559 & 0.016 & 0.612 & 0.044 & $\begin{array}{l}\text { Dedicator of } \\
\text { cytokinesis } 8\end{array}$ & \\
\hline & & & & & Inflammation & $\begin{array}{l}\text { Immunological } \\
\text { synapse formation }\end{array}$ \\
\hline \multirow[t]{2}{*}{ Myo1f } & 0.740 & 0.017 & 0.767 & 0.023 & Myosin 1F & ATP, acting binding \\
\hline & & & & & $\begin{array}{l}\text { Regulator of anti- } \\
\text { inflammation }\end{array}$ & $\begin{array}{l}\text { Defense response to } \\
\text { Gram }(+) \text { bacterium }\end{array}$ \\
\hline \multirow[t]{2}{*}{ Gas5 } & 0.797 & 0.032 & 0.754 & 0.045 & Growth arrest specific 5 & \\
\hline & & & & & $\begin{array}{l}\text { Molecular function } \\
\text { Response to bacterium }\end{array}$ & \\
\hline \multirow[t]{2}{*}{ Trem/2 } & 0.752 & 0.003 & 0.762 & 0.019 & $\begin{array}{l}\text { Triggering receptor } \\
\text { expressed on myeloid } \\
\text { cells-like } 2\end{array}$ & \\
\hline & & & & & $\begin{array}{l}\text { Regulation of innate } \\
\text { immune response }\end{array}$ & \\
\hline \multirow[t]{3}{*}{ Ralbp 1} & 1.999 & $<0.001$ & 0.945 & 0.024 & ralA binding protein 1 & $\begin{array}{l}\text { ATPase activity / } \\
\text { nrotein binding }\end{array}$ \\
\hline & & & & & $\begin{array}{l}\text { Promotion of pro- } \\
\text { inflammatory cytokine } \\
\text { (in obesity) }\end{array}$ & $\begin{array}{l}\text { Positive regulation of } \\
\text { GTPase activity }\end{array}$ \\
\hline & & & & & & Signal transduction \\
\hline \multirow[t]{3}{*}{ Lpar2 } & 1.092 & 0.721 & 1.525 & 0.001 & $\begin{array}{l}\text { Lymphosphatidic acid } \\
\text { receptor } 2\end{array}$ & PDZ domain binding \\
\hline & & & & & Negative regulatory & $\begin{array}{l}\text { Positive regulation of } \\
\text { MAPK cascade }\end{array}$ \\
\hline & & & & & airway inflammation & $\begin{array}{l}\text { G-protein coupled } \\
\text { receptor signaling } \\
\text { pathway }\end{array}$ \\
\hline \multicolumn{7}{|c|}{ Hippocampal functionality / Nervous system } \\
\hline \multirow[t]{2}{*}{ Lrrn4 } & 1.482 & 0.010 & 1.526 & 0.008 & $\begin{array}{l}\text { Leucine rich repeat } \\
\text { neuronal } 4\end{array}$ & Molecular function \\
\hline & & & & & & Long-term memory \\
\hline
\end{tabular}




\begin{tabular}{|c|c|c|c|c|c|c|}
\hline & & & & & $\begin{array}{l}\text { Hippocampus- } \\
\text { dependent long-lasting } \\
\text { memory }\end{array}$ & \\
\hline \multirow[t]{3}{*}{ S100a10 } & \multirow[t]{3}{*}{1.518} & \multirow[t]{3}{*}{0.028} & \multirow[t]{3}{*}{1.677} & \multirow[t]{3}{*}{0.004} & \multirow[t]{2}{*}{$\begin{array}{l}\text { S100 calcium binding } \\
\text { protein A10 (calpactin) }\end{array}$} & Ion channel binding \\
\hline & & & & & & Protein binding \\
\hline & & & & & Hippocampus & $\begin{array}{l}\text { Positive regulation of } \\
\text { GTPase activity }\end{array}$ \\
\hline \multirow[t]{3}{*}{ Slc5a7 } & \multirow[t]{3}{*}{0.675} & \multirow[t]{3}{*}{0.017} & \multirow[t]{3}{*}{0.723} & \multirow[t]{3}{*}{0.045} & \multirow{3}{*}{$\begin{array}{l}\text { Solute carrier family } 5 \\
\text { (choline transporter), } \\
\text { member } 7 \\
\text { Hippocampus }\end{array}$} & $\begin{array}{l}\text { Choline binding/ } \\
\text { choline } \\
\text { transmembrane } \\
\text { transporter activity }\end{array}$ \\
\hline & & & & & & $\begin{array}{l}\text { Acetylcholine } \\
\text { biosynthetic process }\end{array}$ \\
\hline & & & & & & Choline transport \\
\hline \multirow[t]{3}{*}{ Wnt6 } & \multirow[t]{3}{*}{0.818} & \multirow[t]{3}{*}{0.098} & \multirow[t]{3}{*}{0.729} & \multirow[t]{3}{*}{$<0.001$} & \multirow[t]{3}{*}{$\begin{array}{l}\text { Wingless-type MMTV } \\
\text { integration site family, } \\
\text { member } 6\end{array}$} & $\begin{array}{l}\text { Protein / signaling } \\
\text { receptor binding }\end{array}$ \\
\hline & & & & & & Neuron differentiation \\
\hline & & & & & & $\begin{array}{l}\text { Positive regulation of } \\
\text { gene expression }\end{array}$ \\
\hline
\end{tabular}

\section{Scopolamine Treatment Increases Pro-inflammatory Cytokines and Inflammasome Components in the Hippocampus}

Based on the changes of inflammatory genes in RNA sequencing analysis, the levels of pro-inflammatory cytokines were measured from the hippocampal samples using ELISA to compare the effects of surgery and scopolamine on the inflammatory reaction (Fig. 4). Both surgery and scopolamine-treated mice showed significantly increased level of pro-inflammatory cytokines (TNF-a, IL-1 $\beta$, and IL-18) (Fig. 4A, B, and $\mathrm{C}$ ). The levels of pro-inflammatory cytokines IL-1 $\beta$ and IL-18 are regulated by inflammasome. Therefore, we measured protein levels of inflammasome components in the hippocampus. The expression level of NLRP3 inflammasome components such as NLRP3, ASC, and caspase-1 in the hippocampus were significantly upregulated in both the surgery and scopolamine-treated groups, as compared to the control (Fig. 4D, E, and F).

\section{Scopolamine Treatment Promotes Delirium-like Anxiety And Hyper-activation In Mice}

We measured the level of anxiety to investigate whether scopolamine administration could lead to psychological disturbance, a characteristic trait of delirium. Mice behavior tests were conducted using EPM and OFT (Fig. 5). Mice exhibiting the state of anxiety are known to display a tendency of staying in the closed arms of the EPM, thus, scopolamine-treated mice spent significantly less amount of time in the open arms as compared to mice from the control and surgery groups, while surgery mice also showed less time in open arms, as compared to those in the control group (Fig. 5A). In OFT, there was no 
significant difference between the total distance travelled by the control and surgery group mice, However, mice in the scopolamine-treated group exhibited hyperactive motor activity resulting in significantly greater total distance travelled, as compared to mice in the surgery group (Fig. 5B). High activity is used as an index of low emotionality ${ }^{25}$. Additionally, scopolamine-treated mice showed lesser distance travelled in the central zone of the OFT (Fig. 5C), suggesting increased level of anxiety. The SMART video tracking system showed visual tracking of each group in EPM and OFT (Fig. 5D and E).

\section{Scopolamine-treated Mice Display Pro-inflammatory Cytokines and Inflammasome Components in the Prefrontal Cortex and Amygdala}

The prefrontal cortex and amygdala are engaged in emotional response and mood regulation, such as anxiety and depression ${ }^{26}$. We further checked the levels of pro-inflammatory cytokines and NLRP3 inflammasome components in the prefrontal cortex and amygdala (Fig. 6). Compared to the control group, levels of pro-inflammatory cytokines, such as TNF-a, IL-1区, and IL-18, were remarkably higher in the surgery group mice. Additionally, mice of the scopolamine-treated group showed increased levels of TNFa, IL-1区, and IL-18; although, IL-1囚 and IL-18 protein levels in scopolamine-treated mice were significantly reduced as compared to those in the surgery group (Fig. 6A, B, and C). The levels of NLRP3 inflammasome components, such as NLRP3, ASC, and caspase-1, were highly expressed in the prefrontal cortex and amygdala postusrgery. Similar to the surgery group, the scopolamine-treated group showed increased levels of NLRP3 inflammasome components in the prefronal cortex. Furthermore, the levels of NLRP3 in the amygdala were different between mice in the surgery and scopolamine-treated groups with no incremental changes in the latter. However, ASC and caspase-1 expressions were higher in the scopolamine-treated group (Fig. 6D, E, and F).

\section{Discussion}

In the present study, scopolamine-treated animals and postsurgery animals both showed characteristic delirium-like behavioral patterns, and the biochemical findings were coherent with neuroinflammatory changes. RNA sequencing profiles also showed consistent changes in gene expression patterns relevant to immune/inflammatory reaction and nervous system development in both the surgery and scopolamine-treated groups, though there are some discrepancies in the expression patterns of inflammation-related genes. These results suggest the compatibility of scopolamine-treated delirium animal model in re-enacting the clinical features of POD, although there could still be undisclosed pathophysiology and insufficient explanation for neuroinflammatory-based POD.

The cholinergic neurotransmitter system is responsible for the control of cognitive processes, acquisition, and retention of information as well as task performances. Numerous studies have reported the role of cholinergic function in age-related memory dysfunction and other neurocognitive diseases 27,28 .

Scopolamine is known to reproduce delirium-like state in both human and experimental animals ${ }^{29-31}$ by inducing dysregulation of cholinergic signals in the brain; such cognitive declining properties of scopolamine have contributed to its wide application in neurocognitive research. Oxidative stress has 
also been proposed as the possible cause of neurocognitive disease along with the cholinergic hypothesis. Regarding the use of scopolamine, previous studies have reported the association of systemic administration of scopolamine with increased oxidative stress in the brain, especially the areas associated with memory and learning, such as the hippocampus and prefrontal cortex, some of which are reported to be involved in mitochondrial dysfunction ${ }^{15,32}$. Furthermore, scopolamine-induced memory impairment is successfully attenuated by several anti-oxidant compounds, emphasizing the crucial role of oxidative stress in scopolamine-induced amnesia ${ }^{14,33}$. Although dysregulation of the cholinergic system and oxidative stress have been a promising hypothesis explaining pathogenesis for POCD and delirium, increased inflammation still plays an important part in explaining the development of neurocognitive disorders, of which increased level of pro-inflammatory cytokines, such as TNF-a IL-1 $\beta$, IL18 , and IL-6, can be observed in the brain and blood samples of patients with dementia, delirium, and POCD ${ }^{34-36}$. Scopolamine administration has also been shown to cause increase in pro-inflammatory cytokines, and inflammation has been proposed as the theoretical basis for scopolamine-induced memory impairment ${ }^{15,37}$. The significance of neuroinflammation in delirium is consistent with our results showing the increase of pro-inflammatory cytokines in both the surgery and scopolamine-treated groups.

NLRP3 inflammasome, an intracellular sensor that detects a broad range of microbial motifs, has been demonstrated to increase the level of pro-inflammatory cytokines such as IL-1 $\beta$ and IL-18 in the brain by activating caspase $-1^{38}$. NLRP3 inflammasome further promotes the aggregation of innate immune cells and initiates the downstream inflammatory cascade that ultimately accelerates the pathological progression of neurocognitive disease ${ }^{38-40}$. Its activation had been the marker for host immune defense mechanism in various inflammatory diseases with no exceptions to the development of neurodegenerative disorders. In this study, the activation of NLRP3 inflammasome was observed in three different brain regions, of which the hippocampal area of scopolamine-treated mice showed increased activation. Increased activation of NLRP3 inflammasome was also seen in the hippocampus of surgery mice implying POCD. Therefore, NLRP3 inflammasome may be the main cause of cognitive impairment after surgery as well as scopolamine treatment.

Amygdala is the brain region crucial for executive function, memory, attention, and especially for the pathogenesis of delirium, along with the frontal lobes, diencephalon and hippocampus ${ }^{31,41}$. In addition, the dysregulated prefrontal cortex-to-amygdala pathway is associated with anxiety ${ }^{26}$. Previous studies have shown the significant diminution of neurotransmitters, including dopamine, 3,4-dihydroxyphenylacetic acid (DOPAC), homovanillic acid (HVA), and acetylcholine, in the amygdala of scopolaminetreated animals as compared to control group animals and also compared to the hippocampus area within the same scopolamine-treated groups ${ }^{31,41}$. In addition, evidences has also suggested altered neurotransmission especially in the regions related to memory, such as the hippocampus and amygdala, in relation to outcomes seen in POD. The significance of inflammasome is very important in the neuroinflammatory-based hypothesis for POD. In the present study, levels of NLRP3 inflammasome components were all higher in the prefrontal cortical area of scopolamine-treated mice; however, the expression level was different in the amygdala, showing increase in inflammasome components levels 
after scopolamine treatment, but not in NLRP3 levels. Detailed explanation for transition aspects of NLRP3 inflammasome in the amygdala could be limited due to restricted information focusing on the direct changes of inflammasome in the amygdala, of which reduced expression of NLRP3 inflammasome can only be indirectly inferred from altered or abnormal expression of neurotransmitters in the amygdala or other kinds of inflammasome complexes (e.g. NLRP2, NLRC4, and AIM2) might be involved in the pathogenesis of delirium.

RNA sequencing analysis technique has been widely used for various human disease, and a large amount of genetic data has been produced over the past decades from various diseases. With the help of RNA sequencing analysis from different treatment groups, this study successfully identified the altered gene expression patterns from each group to further investigate the reliability of scopolamine-treated animal models as compatible delirium model from neuroinflammatory point of view. This study also identified the genes with significant expression profiles related to inflammation and the development of the nervous system that presented with a more distinct expression pattern in surgery mice as compared with scopolamine- treated mice (Table 1). For example, gene expression of Ralbp 1, which was significantly upregulated in surgery mice compared to control mice and downregulated in scopolaminetreated mice compared to surgery mice, plays a role in receptor-mediated endocytosis and is a downstream effector of the small GTP-binding protein RAL ${ }^{42}$. Ralbp 1 is known for its oncogenic role and necessary role in cell proliferation and invasion in carcinogenesis ${ }^{43}$, and it is also known for regulating obesity-promoting pro-inflammatory cytokines ${ }^{44}$. Lpar2 encodes a member of family I of the $G$ proteincoupled receptors, as well as the endothelial cell differentiation gene (EDG) family of proteins. Lysophosphatidic acid signaling via receptors regulates diverse malignant cellular functions such as cell proliferation, motility, invasion, and metastasis ${ }^{45}$. Furthermore, Lpar2 antagonism prevents aging-related cognitive impairment in mice ${ }^{46}$. From the inflammation and immune perspective, $L$ par2 functions as the negative regulator for innate immune response to prevent excess inflammation, tissue injury, and to promote homeostasis, with increased expression of Lpar2 to suppress T-helper type 2 (Th2)-driven inflammation in mice models ${ }^{47}$. Lpar2 gene expression was upregulated 1.5 times in scopolaminetreated mice, while no dramatic changes were seen in surgery mice in this study. This could imply the possible suppression of Th2-driven inflammation followed by increased expression of $L$ par2, despite the decreased acetylcholine (Ach) level seen in scopolamine-treated group, since Ach is known to modulate key processes of the allergic inflammatory response via muscarinic and nicotinic receptors ${ }^{48}$. Increased levels of Ach are known to activate Th2 differentiation and polarization via native T cells and dendritic cells, respectively ${ }^{48}$. Such changes in the Ach level from scopolamine treatment could also affect the inflammatory and immune response via $L$ par2 expression levels in scopolamine-treated mice group.

However, gene expression patterns from both the surgery and scopolamine-treated groups showed that a number of notable genes were associated with the analogous cellular functions, mostly focusing on inflammatory reactions and the development of the neuronal system, although expression levels and significance vary to some extent. For example, Dhx 58 coding LGP2, is related to the regulation of innate immune response, immune system, and apoptosis during viral infection ${ }^{49}$. Myo $1 f$ encodes myosin-1F 
protein and is expressed mainly in the immune system ${ }^{50}$. It is involved in the regulation of M1polarization during the inflammatory process, whereas Myo1 $f$ deficiency is known to attenuate the commitment of macrophages into a pro-inflammatory phenotype. Myo $1 \mathrm{f}$ deficiency model strongly reduces the secretion of pro-inflammatory cytokines, decreases epithelial damage, ameliorates disease activity, and enhances tissue repair ${ }^{51,52}$. Trem/2 is a transmembrane protein family, which expresses in various immune cells, such as monocytes, macrophage, and microglia. Trem/2 is involved in innate and adaptive immunity and causes increase in number of macrophages under inflammatory condition ${ }^{53}$.

Another gene, Lrrn4, which was upregulated in both the surgery and scopolamine-treated groups, is a protein coding gene playing a crucial role in hippocampus-dependent long lasting memory ${ }^{54}$. S100a10 encodes a member of the $\mathrm{S} 100$ family of protein containing 2 EF-hand calcium-binding motifs called S100A10 or p11, which are involved in the regulation of various cellular processes such as cell cycle progression and differentiation. Upregulated levels of S100a10 in the hippocampus engage in processing emotional memory and altered hippocampal functionality ${ }^{55}$, which is due to the interaction of p11 with serotonin-signaling proteins. Moreover, as cognitive impairments are common in delirium due to dysfunctional serotonin neurotransmission, p11 protein is known to interact with serotonin-signaling proteins and correlate with symptoms of mood disorders ${ }^{55,56}$. Sc/5a7 is implicated in the delivery of the precursor choline from the synaptic space into presynaptic terminal, which is important in cholinergic neuronal communication ${ }^{57}$. To summarize, scopolamine administration can successfully reproduce characteristic neuropsychiatric behavioral changes of delirium in accordance with neuroinflammatory hypothesis, although less consistency was noted in descriptive RNA sequencing analysis studies. In this study, we have only suggested candidate genes involved in scopolamine-treatment delirium. Therefore, further studies focusing on delirium and the involvement of candidate genes for pathophysiological studies are needed.

Delirium represents the large spectrum of cognitive and behavioral abnormalities from hypoactive form, with negative symptoms of inattention and flat affect, to hyperactive form with characteristic agitation and anxiousness ${ }^{58}$. In this study, neurobehavioral tests showed significant increase in the level of anxiety and hyper motor activity, and impairment in memory and cognitive function in scopolaminetreated group; this seems to be associated with increased level of inflammatory response. Scopolamine is particularly known to damage learning and short-term memory functions in rodents and humans by disrupting cholinergic transmission ${ }^{15}$, which makes it the most widely used drug for reproducing delirium in animal. However, disagreements regarding altered cognitive function in scopolamine-treated delirium animal models, perhaps due to lack of credibility of neurobehavioral tests, especially those focusing on cognition, were also witnessed. Different neurobehavioral changes could possibly be due to a large spectrum of behavioral delirium, or potentiality of other distinct mechanisms underlying the development of cognitive dysfunction, apart from the disruption of cholinergic transmission by scopolamine. For one reason or another, inconsistent findings of neurobehavioral patterns obtained from the tests raise doubts on the credibility of scopolamine-treated delirium animal models in re-enacting characteristic findings of 
delirium in humans. Thereby, the reliability of scopolamine treatment as a standard protocol for reproducing delirium via neuroinflammation-based pathophysiology still needs to be studied further.

In conclusion, our results show that scopolamine-induced POD animal models had succeeded in showing the analogous neurobehavioral patterns, and thus, present findings coherent with neuroinflammatory reactions in POD. However, genetic analysis showed the limitations as an indispensable explanation between candidate genes and delirium. Undeniably, further studies addressing the possible interactions between delirium and candidate genes after scopolamine treatment for pathophysiological studies are necessary.

\section{Declarations}

\section{Acknowledgements}

This study was supported by the National Research Foundation of Korea (NRF) grants funded by the Korean government (MSIT) (No.2017R1C1B5017506) to Eun Jung Kim and (No.2020R1A2C1012166) to Bon-Nyeo Koo.

\section{Author's Contributions}

BNK and EJK designed this study. EHK performed the experiments. EJK SYK, and JN analysed the results. EJK and SYC wrote the manuscript. EJK, SYC, and EHK prepared the figures. BNK and EJK finalized the manuscript. All authors read and approved the final version of this manuscript.

\section{Ethics Declarations}

The authors declare no conflicts of interest.

\section{References}

1. Deiner, S. \& Silverstein, J. H. Postoperative delirium and cognitive dysfunction. BJA: British Journal of Anaesthesia. 103, i41-i46 (2009).

2. Krenk, L. \& Rasmussen, L. S. Postoperative delirium and postoperative cognitive dysfunction in the elderly - what are the differences?. Minerva Anestesiol. 77, 742-749 (2011).

3. Inouye, S. K. Delirium in older persons. N Engl J Med. 354, 1157-1165 (2006).

4. Saczynski, J. S. et al. Cognitive trajectories after postoperative delirium. N Engl J Med. 367, 30-39 (2012).

5. Witlox, J. et al. Delirium in elderly patients and the risk of postdischarge mortality, institutionalization, and dementia: a meta-analysis. Jama. 304, 443-451 (2010).

6. Skvarc, D. R. et al. Post-Operative Cognitive Dysfunction: An exploration of the inflammatory hypothesis and novel therapies. Neuroscience and biobehavioral reviews. 84, 116-133 (2018). 
7. Leslie, M. The post-op brain. Science. 356, 898-900 (2017).

8. Hoover, D. B. Cholinergic modulation of the immune system presents new approaches for treating inflammation. Pharmacol Ther. 179, 1-16 (2017).

9. Tata, A. M., Velluto, L., D'Angelo, C. \& Reale, M. Cholinergic system dysfunction and neurodegenerative diseases: cause or effect?. CNS Neurol Disord Drug Targets. 13, 1294-1303 (2014).

10. Kilimann, I. et al. Parallel Atrophy of Cortex and Basal Forebrain Cholinergic System in Mild Cognitive Impairment. Cereb Cortex. 27, 1841-1848 (2017).

11. Bonaz, B., Sinniger, V. \& Pellissier, S. Anti-inflammatory properties of the vagus nerve: potential therapeutic implications of vagus nerve stimulation. The Journal of physiology. 594, 5781-5790 (2016).

12. Field, R. H., Gossen, A. \& Cunningham, C. Prior pathology in the basal forebrain cholinergic system predisposes to inflammation-induced working memory deficits: reconciling inflammatory and cholinergic hypotheses of delirium. The Journal of neuroscience: the official journal of the Society for Neuroscience. 32, 6288-6294 (2012).

13. Hshieh, T. T., Fong, T. G., Marcantonio, E. R. \& Inouye, S. K. Cholinergic deficiency hypothesis in delirium: a synthesis of current evidence. J Gerontol A Biol Sci Med Sci. 63, 764-772 (2008).

14. Rahimzadegan, M. \& Soodi, M. Comparison of Memory Impairment and Oxidative Stress Following Single or Repeated Doses Administration of Scopolamine in Rat Hippocampus. Basic Clin Neurosci. 9, 5-14 (2018).

15. Wong Guerra, M. et al. Mitochondrial involvement in memory impairment induced by scopolamine in rats. Neurological research. 39, 649-659 (2017).

16. Demirci, K., Naziroglu, M., Ovey, I. S. \& Balaban, H. Selenium attenuates apoptosis, inflammation and oxidative stress in the blood and brain of aged rats with scopolamine-induced dementia. Metab Brain Dis. 32, 321-329 (2017).

17. Ishola, I. O. et al. Protective effect of Cnestis ferruginea and its active constituent on scopolamineinduced memory impairment in mice: a behavioral and biochemical study. Pharm Biol. 51, 825-835 (2013).

18. Drevets, W. C., Zarate, C. A. Jr. \& Furey, M. L. Antidepressant effects of the muscarinic cholinergic receptor antagonist scopolamine: a review. Biol Psychiatry. 73, 1156-1163 (2013).

19. Lee, J. S. et al. Hippocampal memory enhancing activity of pine needle extract against scopolamineinduced amnesia in a mouse model. Sci Rep. 5, 9651 (2015).

20. Hovens, I. B. et al. Postoperative cognitive dysfunction: Involvement of neuroinflammation and neuronal functioning. Brain Behav Immun. 38, 202-210 (2014).

21. Barrientos, R. M., Hein, A. M., Frank, M. G., Watkins, L. R. \& Maier, S. F. Intracisternal interleukin-1 receptor antagonist prevents postoperative cognitive decline and neuroinflammatory response in aged rats. The Journal of neuroscience: the official journal of the Society for Neuroscience. 32, 14641-14648 (2012). 
22. Lipkind, D. et al. New replicable anxiety-related measures of wall vs center behavior of mice in the open field. J Appl Physiol (1985). 97, 347-359 (2004).

23. Walf, A. A. \& Frye, C. A. The use of the elevated plus maze as an assay of anxiety-related behavior in rodents. Nat Protoc. 2, 322-328 (2007).

24. Antunes, M. \& Biala, G. The novel object recognition memory: neurobiology, test procedure, and its modifications. Cogn Process. 13, 93-110 (2012).

25. Seibenhener, M. L. \& Wooten, M. C. Use of the Open Field Maze to measure locomotor and anxietylike behavior in mice.J Vis Exp,e52434(2015).

26. Liu, W. Z. et al. Identification of a prefrontal cortex-to-amygdala pathway for chronic stress-induced anxiety. Nat Commun. 11, 2221 (2020).

27. Furey, M. L. The prominent role of stimulus processing: cholinergic function and dysfunction in cognition. Curr Opin Neurol. 24, 364-370 (2011).

28. Hampel, H. et al. The cholinergic system in the pathophysiology and treatment of Alzheimer's disease. Brain: a journal of neurology. 141, 1917-1933 (2018).

29. Lin, Y. G. et al. Delirium due to scopolamine patch in a 4-year-old boy. J Formos Med Assoc. 110, 208-211 (2011).

30. He, D. et al. Effects of harmine, an acetylcholinesterase inhibitor, on spatial learning and memory of APP/PS1 transgenic mice and scopolamine-induced memory impairment mice. European journal of pharmacology. 768, 96-107 (2015).

31. Qiu, Y. et al. Neuroprotective effects of HTR1A antagonist WAY-100635 on scopolamine-induced delirium in rats and underlying molecular mechanisms. BMC Neurosci. 17, 66 (2016).

32. Ponne, S., Kumar, C. R. \& Boopathy, R. Verapamil attenuates scopolamine induced cognitive deficits by averting oxidative stress and mitochondrial injury - A potential therapeutic agent for Alzheimer's Disease. Metab Brain Dis. 35, 503-515 (2020).

33. Harrison, F. E., Hosseini, A. H., Dawes, S. M., Weaver, S. \& May, J. M. Ascorbic acid attenuates scopolamine-induced spatial learning deficits in the water maze. Behav Brain Res. 205, 550-558 (2009).

34. Akiyama, H. et al. Cell mediators of inflammation in the Alzheimer disease brain. Alzheimer Dis Assoc Disord. 14 (Suppl 1), S47-53 (2000).

35. Simone, M. J. \& Tan, Z. S. The role of inflammation in the pathogenesis of delirium and dementia in older adults: a review. CNS Neurosci Ther. 17, 506-513 (2011).

36. Peng, L., Xu, L. \& Ouyang, W. Role of peripheral inflammatory markers in postoperative cognitive dysfunction (POCD): a meta-analysis. PLoS One. 8, e79624 (2013).

37. Ahmad, A., Ramasamy, K., Jaafar, S. M., Majeed, A. B. \& Mani, V. Total isoflavones from soybean and tempeh reversed scopolamine-induced amnesia, improved cholinergic activities and reduced neuroinflammation in brain. Food Chem Toxicol. 65, 120-128 (2014). 
38. He, Y., Hara, H. \& Núñez, G. Mechanism and Regulation of NLRP3 Inflammasome Activation. Trends Biochem Sci. 41, 1012-1021 (2016).

39. Mangan, M. S. J. et al. Targeting the NLRP3 inflammasome in inflammatory diseases. Nat. Rev. Drug Discovery. 17, 588-606 (2018).

40. Heneka, M. T., McManus, R. M. \& Latz, E. Inflammasome signalling in brain function and neurodegenerative disease. Nat Rev Neurosci. 19, 610-621 (2018).

41. Qiu, Y. et al. 5-HT(1A) receptor antagonist improves behavior performance of delirium rats through inhibiting PI3K/Akt/mTOR activation-induced NLRP3 activity. IUBMB Life. 68, 311-319 (2016).

42. Cantor, S. B., Urano, T. \& Feig, L. A. Identification and characterization of Ral-binding protein 1, a potential downstream target of Ral GTPases. Mol Cell Biol. 15, 4578-4584 (1995).

43. Yan, C. \& Theodorescu, D. R. A. L. Biology and Potential as Therapeutic Targets in Cancer. Pharmacological reviews. 70, 1-11 (2018).

44. Singhal, S. S. et al. RLIP76 protein knockdown attenuates obesity due to a high-fat diet. The Journal of biological chemistry. 288, 23394-23406 (2013).

45. Tsujiuchi, T., Araki, M., Hirane, M., Dong, Y. \& Fukushima, N. Lysophosphatidic acid receptors in cancer pathobiology. Histol Histopathol. 29, 313-321 (2014).

46. Fischer, C. et al. Prevention of age-associated neuronal hyperexcitability with improved learning and attention upon knockout or antagonism of LPAR2.Cell Mol Life Sci(2020).

47. Emo, J. et al. Lpa2 is a negative regulator of both dendritic cell activation and murine models of allergic lung inflammation. J Immunol. 188, 3784-3790 (2012).

48. Bosmans, G. et al. Cholinergic Modulation of Type 2 Immune Responses. Front Immunol. 8, 1873 (2017).

49. Zhu, Z., Zhang, X., Wang, G. \& Zheng, H. The laboratory of genetics and physiology 2: emerging insights into the controversial functions of this RIG-I-like receptor. Biomed Res Int 2014, 960190 (2014).

50. Salvermoser, M. et al. Myosin $1 \mathrm{f}$ is specifically required for neutrophil migration in 3D environments during acute inflammation. Blood. 131, 1887-1898 (2018).

51. Piedra-Quintero, Z. L. et al. Myosin 1F Regulates M1-Polarization by Stimulating Intercellular Adhesion in Macrophages. Frontiers in immunology. 9, 3118-3118 (2019).

52. Kim, S. V. et al. Modulation of cell adhesion and motility in the immune system by Myo1f. Science. 314, 136-139 (2006).

53. Zheng, H. et al. Opposing roles of the triggering receptor expressed on myeloid cells 2 and triggering receptor expressed on myeloid cells-like transcript 2 in microglia activation. Neurobiol Aging. 42, 132-141 (2016).

54. Bando, T. et al. Neuronal leucine-rich repeat protein 4 functions in hippocampus-dependent longlasting memory. Mol Cell Biol. 25, 4166-4175 (2005). 
55. Eriksson, T. M. et al. Bidirectional regulation of emotional memory by 5-HT1B receptors involves hippocampal p11. Mol Psychiatry. 18, 1096-1105 (2013).

56. Warner-Schmidt, J. L. et al. Role of p11 in cellular and behavioral effects of 5-HT4 receptor stimulation. The Journal of neuroscience: the official journal of the Society for Neuroscience. 29, 1937-1946 (2009).

57. Dobransky, T. \& Rylett, R. J. A model for dynamic regulation of choline acetyltransferase by phosphorylation. Journal of neurochemistry. 95, 305-313 (2005).

58. Pun, B. T. \& Ely, E. W. The importance of diagnosing and managing ICU delirium. Chest. 132, 624636 (2007).

\section{Figures}


A
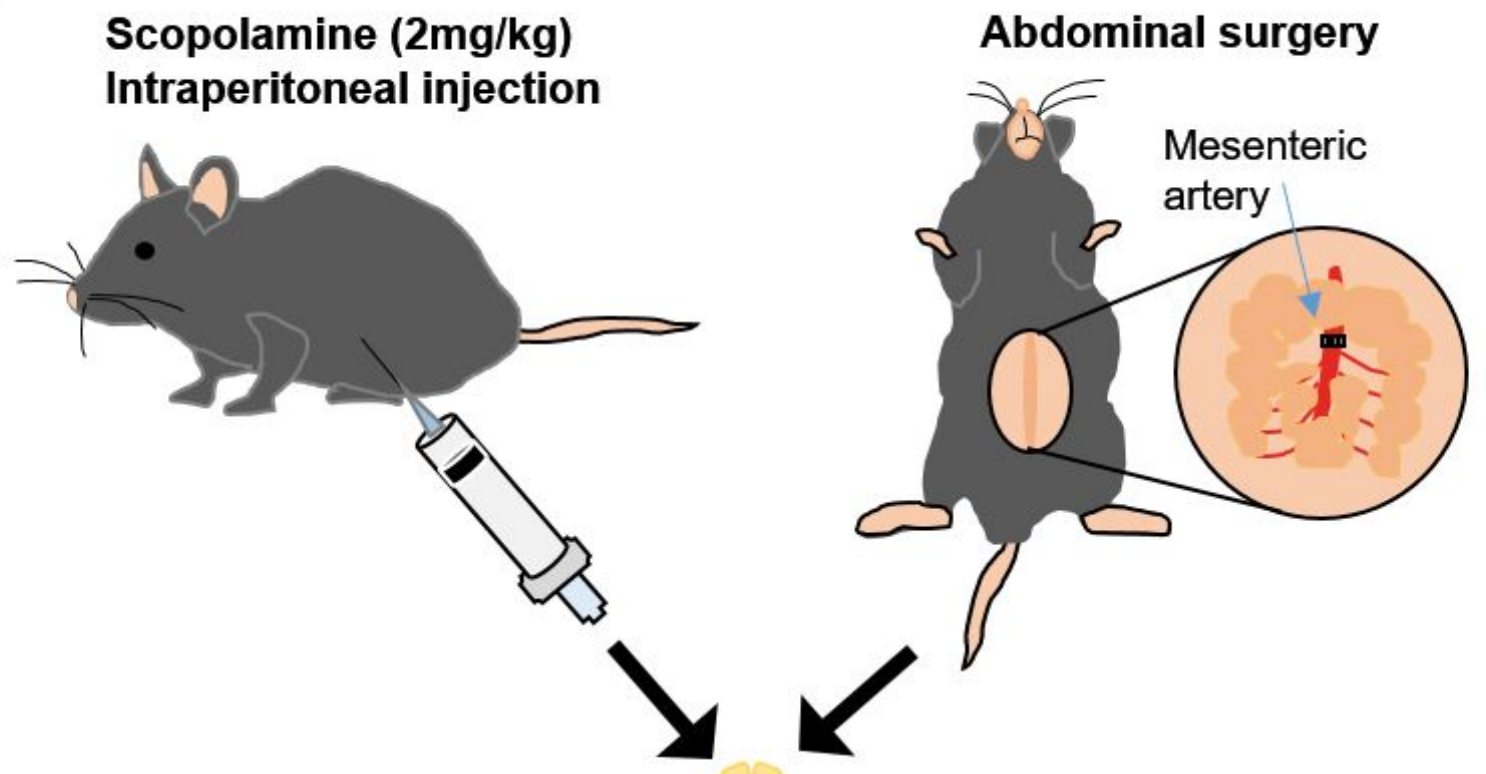

Hippocampus, Amygdala, and Prefrontal cortex

B

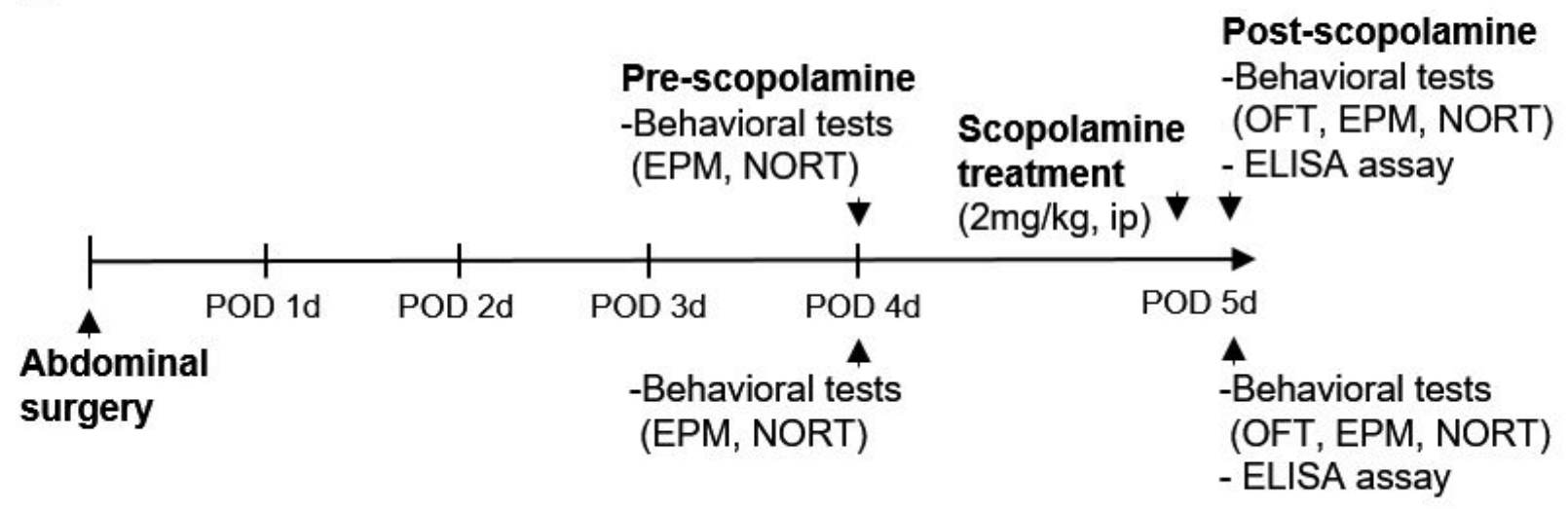

Figure 1

Experimental design and procedure. (A) Scopolamine $(2 \mathrm{mg} / \mathrm{kg}$ ) was injected intraperitoneally. Mice were subjected to abdominal surgery by clipping mesenteric artery and rubbing intestines. All mouse brains were isolated, and brain sub-regions, such as hippocampus, prefrontal cortex, and amygdala, were analyzed after surgery or scopolamine treatment. (B) Mice in surgery group performed behavioral test at 
4 and 5 day post-surgery. Mice in both control and scopolamine-treated group performed behavioral test at 1 day before scopolamine or vehicle treatment.

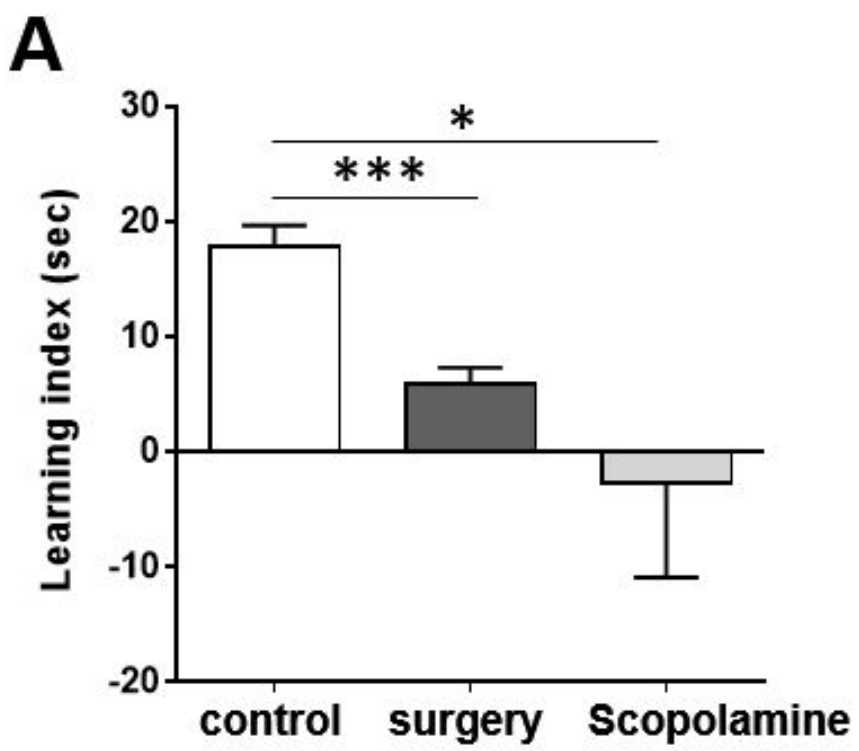

C

Control

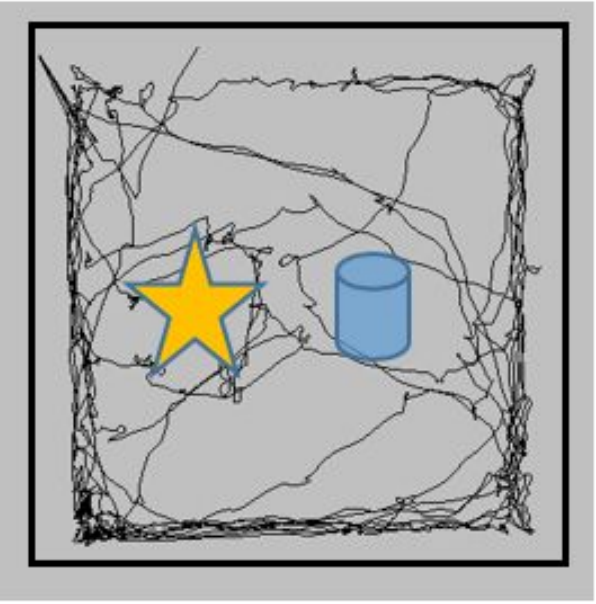

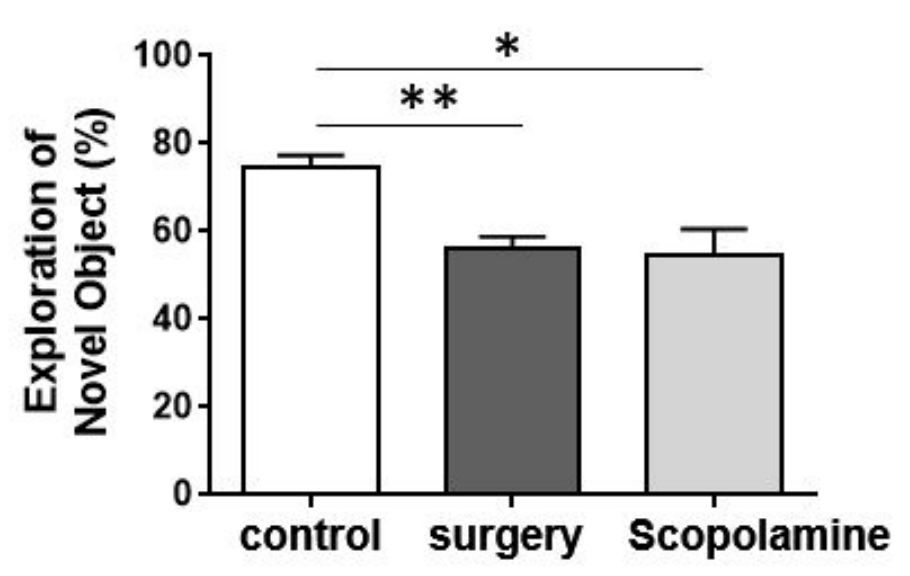

B

Figure 2

Effects of scopolamine on memory dysfunction. (A) Changes in cognition is presented as the learning index in EPM, (B) or the exploration time of novel object in NORT after surgery or scopolamine treatment. (C) Representative activity tracking during OFT. Values are presented as mean \pm SEM $(n=4-5)$. $p$-values < 0.05 were considered significant $\left({ }^{*} p<0.05\right)$. EPM; elevated plus maze, NORT; novel object recognition test. 
A

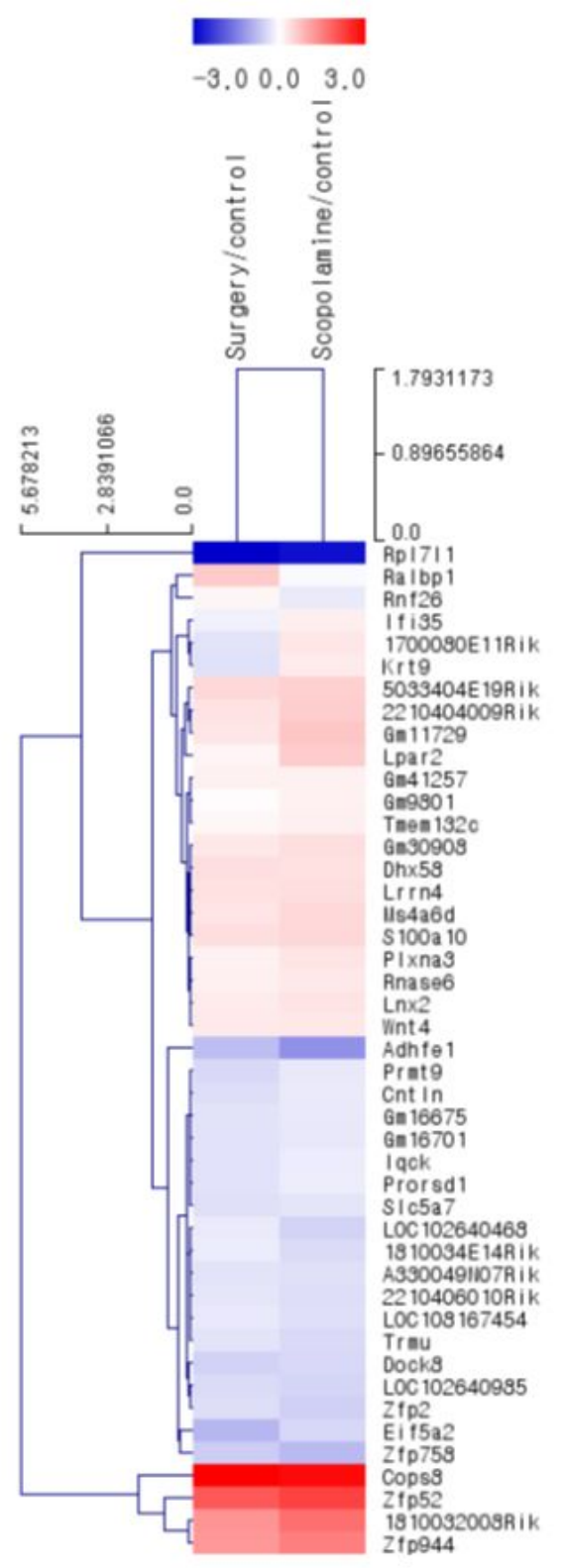

B

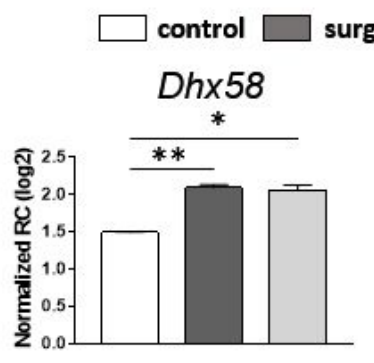

Myo1f

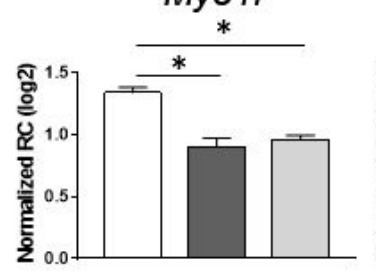

Trem/2

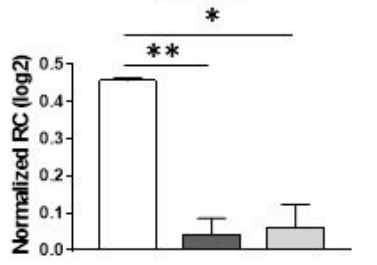

Lpar2

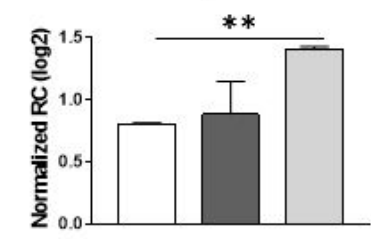

C
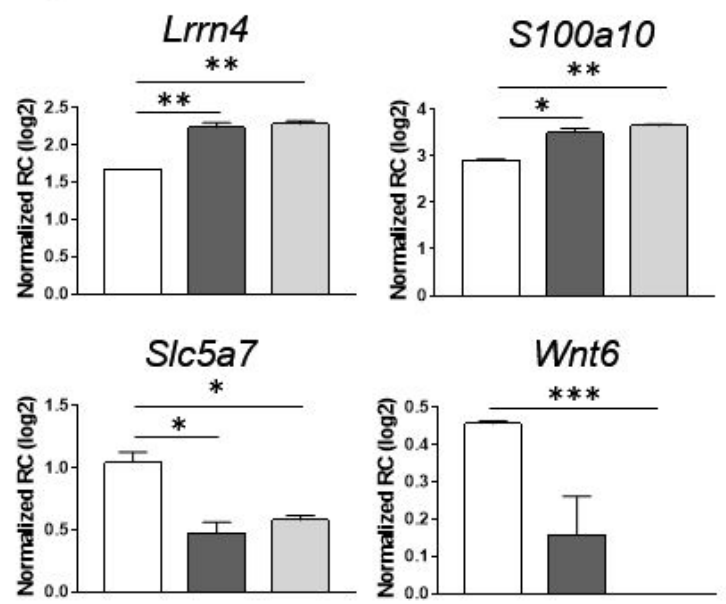

\section{Figure 3}

RNA sequencing transcriptome analysis. (A) Hierarchical clustering of hippocampal samples from control, surgery, and scopolamine-treated groups. Samples were clustered according to the gene expression profiles of differentially expressed genes between control mice and surgery and scopolaminetreated mice, respectively The clustering tree is shown on the left, and the sample clustering tree appears at the top. The color scale shown at the top indicates the relative gene expression levels, with red 
representing a high expression level and blue, a low expression level. (B) Differentially expressed mRNAs involving immune/inflammatory response, and (C) hippocampal functionality and nervous system after surgery or scopolamine treatment. Values are presented as mean \pm SEM $(n=2-3)$. $p$-values $<0.05$ were considered significant $\left({ }^{\star} \mathrm{p}<0.05\right)$.

A

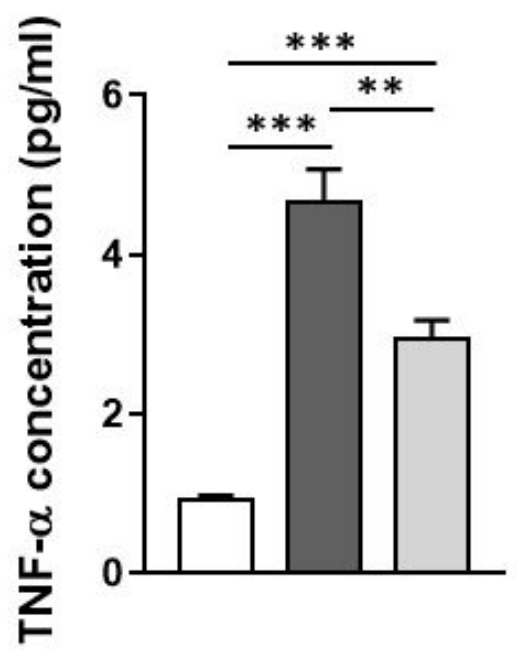

B

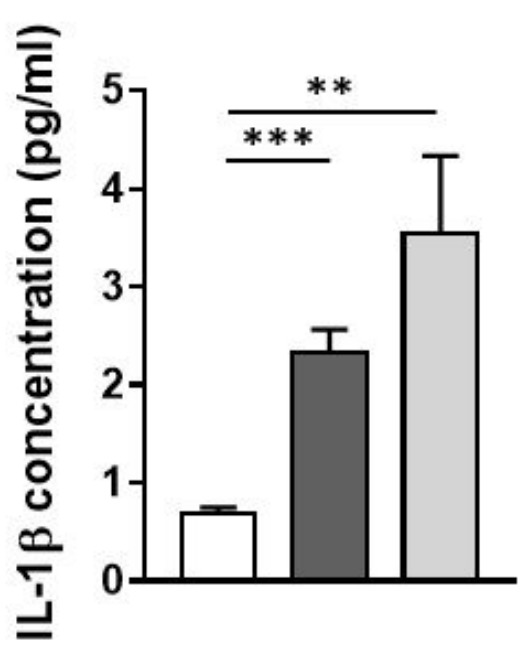

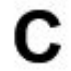

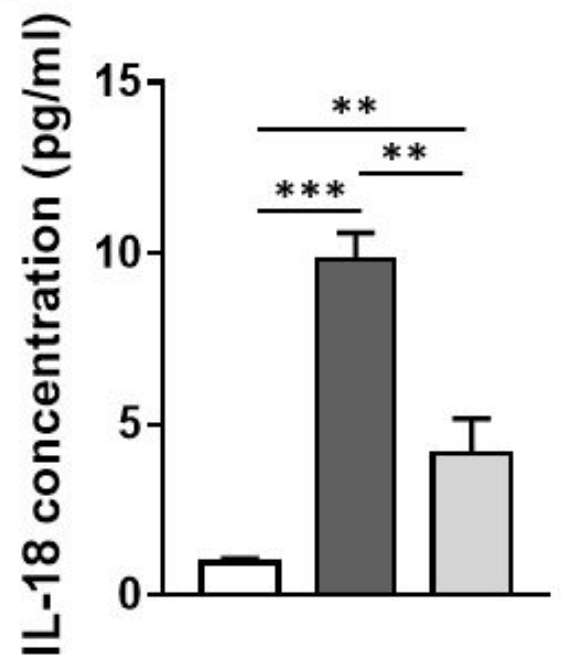

\section{control $\square$ surgery $\square$ scopolamine}
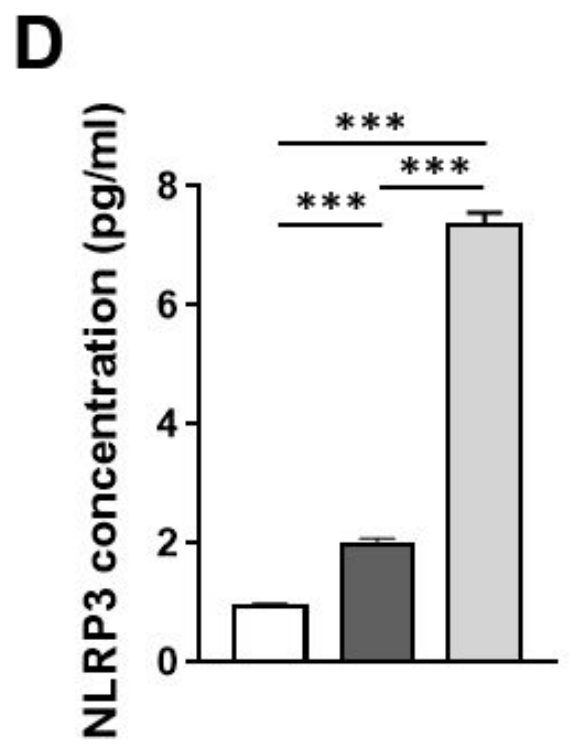

E

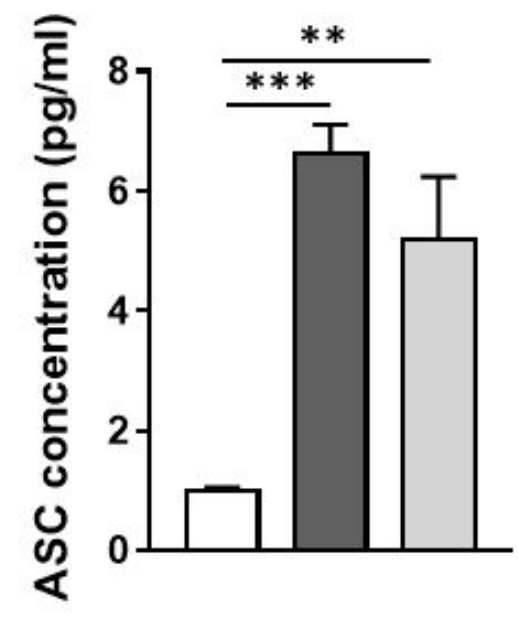

$\mathbf{F}$

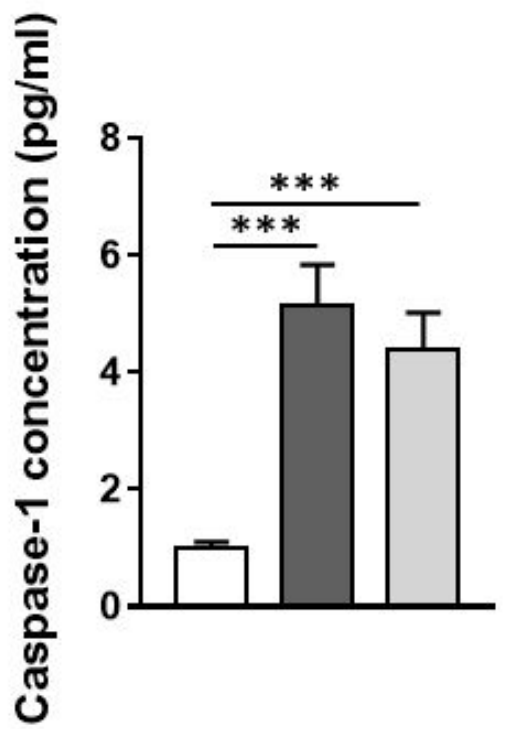

Figure 4

The levels of pro-inflammatory cytokines and NLRP3 inflammasome components in the hippocampus. (A, B and C) Upregulated levels of pro-inflammatory cytokines including TNF-a, IL-1区, and IL-18 in the hippocampus with surgery or scopolamine treatment. (D, E, and F) Increased levels of NLRP3, ASC, ad caspase-1 in the hippocampus with surgery or scopolamine treatment. Values are presented as mean \pm SEM $(n=4-6)$. $p$-values $<0.05$ were considered significant $\left({ }^{*} p<0.05\right)$. 
A

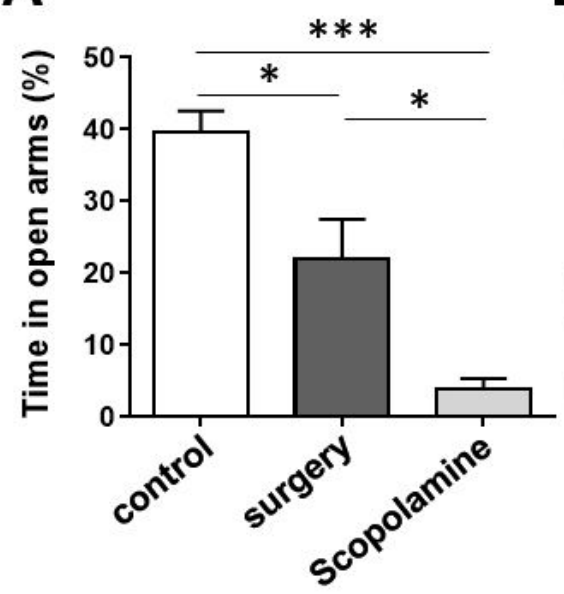

D

Control

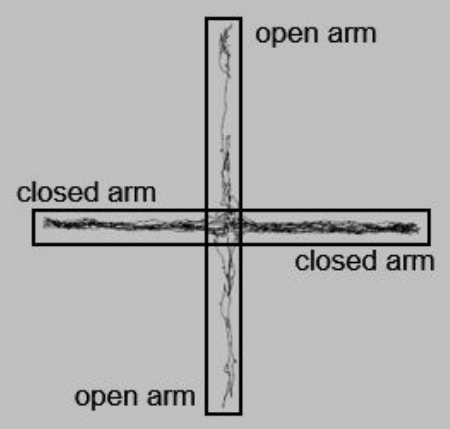

E

\section{Control}

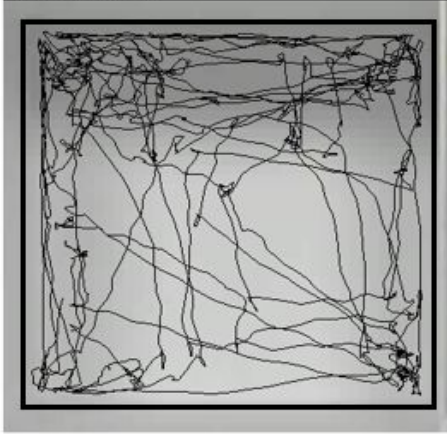

B

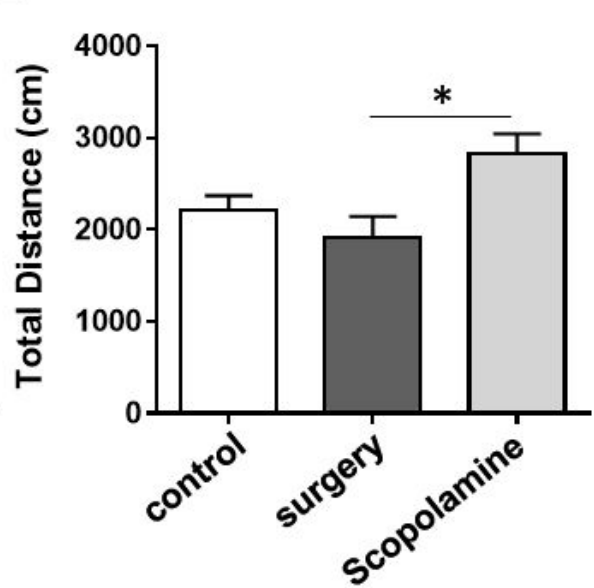

C

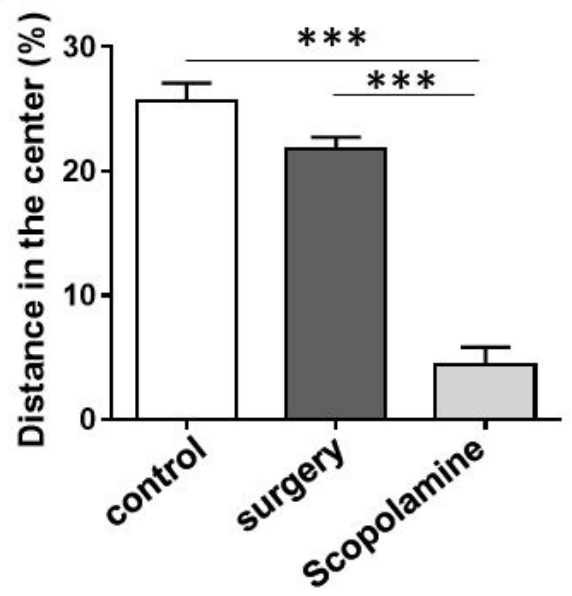

Scopolamine
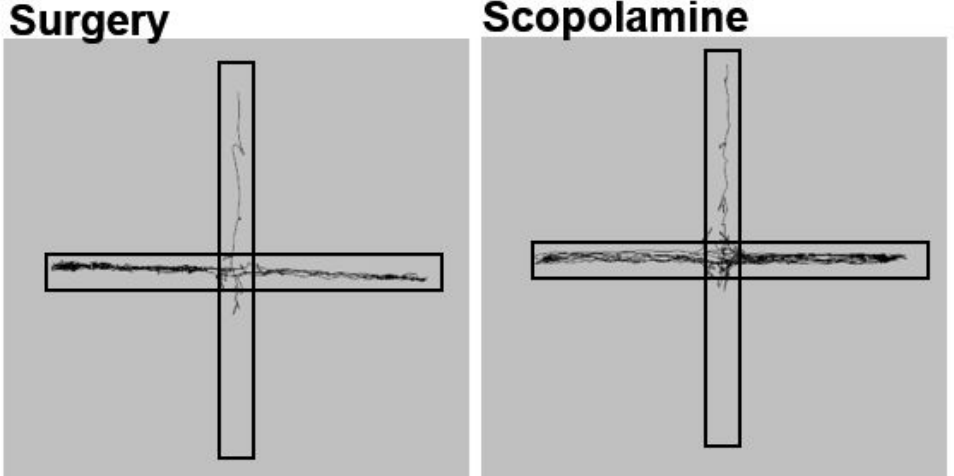

Scopolamine
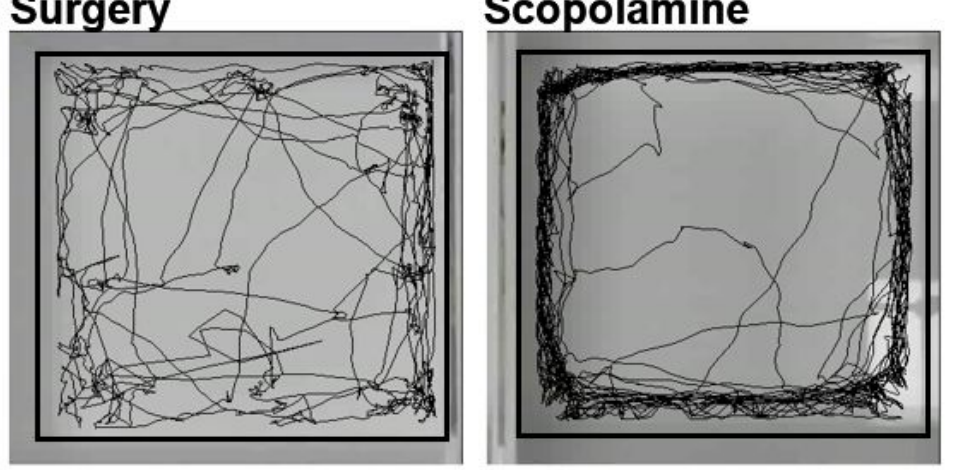

Figure 5

Effects of scopolamine on psychological behaviors. (A) Reduced percentage time in open arms after surgery or scopolamine treatment in EPM. (B) Increased total distance travelled in OFT after scopolamine treatment. (C) Lower distance travelled in center zone of OFT after scopolamine treatment. (D) Representative activity tracking during EPM. (E) Representative activity tracking during OFT. Values are presented as mean \pm SEM $(n=4-5)$. $p$-values $<0.05$ were considered significant $\left({ }^{*} p<0.05\right)$. EPM; elevated plus maze, OFT; open field test 

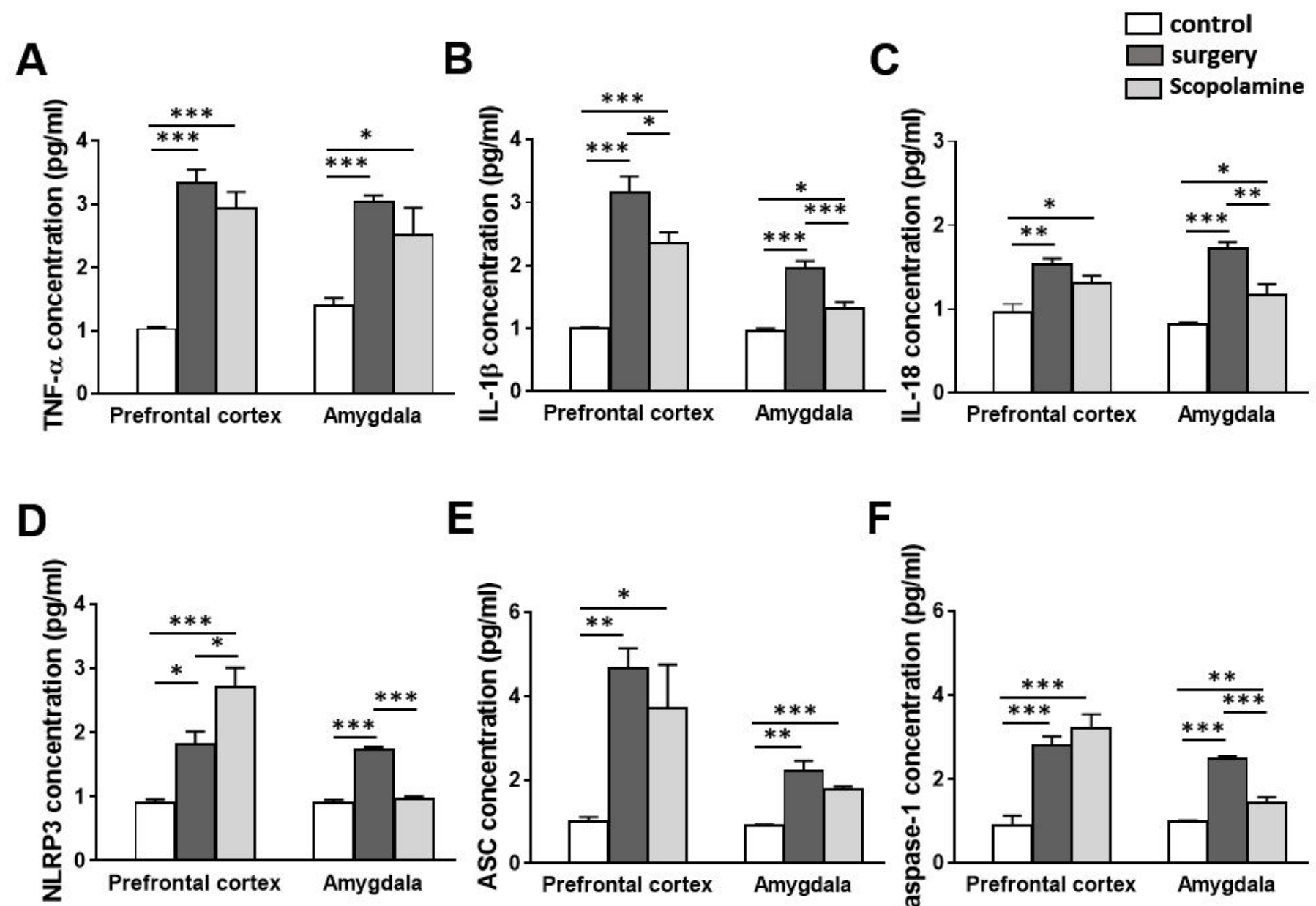

$\mathbf{E}$

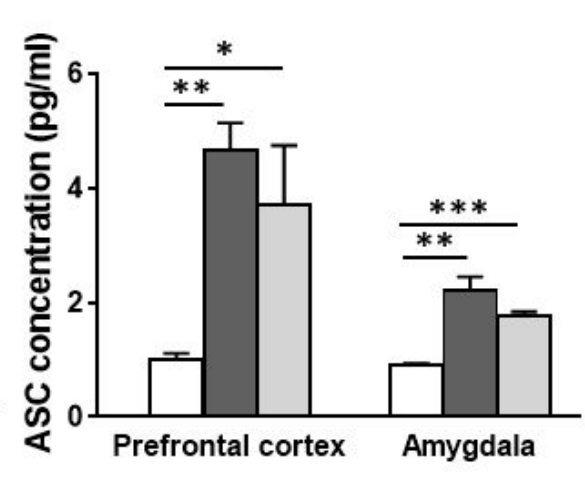

$\mathbf{F}$

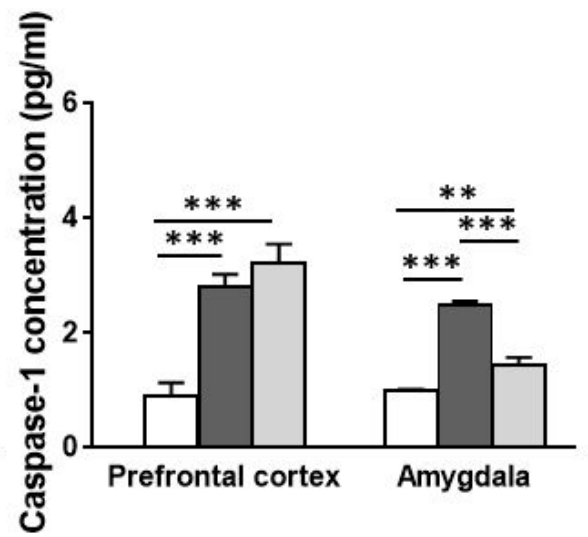

Figure 6

The levels of pro-inflammatory cytokines and NLRP3 inflammasome components in the prefrontal cortex and amygdala. (A, B and C) Increased levels of pro-inflammatory cytokines including TNF-a, IL-1区, and IL18 in the prefrontal cortex and amygdala with surgery or scopolamine treatment. (D, E, and $F$ ) Upregulated levels of NLRP3, ASC, ad caspase-1 in the prefrontal cortex with surgery or scopolamine treatment. Also, increased levels of ASC, ad caspase- 1 in the amygdala with surgery or scopolamine treatment except NLRP3. Values are presented as mean \pm SEM $(n=4-6)$. p-values $<0.05$ were considered significant $\left({ }^{\star} p<0.05\right)$. 